\title{
AURICULAR FIBRILLATION LATE IN THE COURSE OF DIPHTHERIA
}

\author{
BY \\ A. M. G. CAMPBELL, PAUL C. GIBSON, AND C. R. T. LANE \\ Received June 21, 1943
}

Auricular fibrillation has been recorded as occurring in diphtheria during two distinct phases of the disease. During the acute phase, when the heart is gravely damaged, it may be incidental to progressive failure, and, much more rarely, it may be a later manifestation without any other sign of myocardial damage. It is an example of this second type that we record here. It may be some measure of the rarity of the association of auricular fibrillation with diphtheria that of three standard American text-books of cardiology, Fishberg (1940), Pardee (1941), and White (1937), only one (Fishberg) mentions it, and that only in a simple statement that in diphtheria the pulse may be irregular as the result of extrasystoles, auricular fibrillation, and other disturbances of rhythm. Burkhardt et al. (1938) found no case of auricular fibrillation in 140 adults with diphtheria, examined electrocardiographically every second or third day of their stay in hospital. We cannot accept the statement of Neubauer (1942) that 2 of his 100 cases of diphtheria with heart lesions showed transient auricular fibrillation, because, in the only examples he records (his Fig. 14), the rhythm of one is regular in lead III and the irregularity in lead II could be extrasystolic, and in the other (his Fig. 15), who had a severe heart lesion, it cannot be auricular fibrillation for the ventricular rhythm is in fact regular. Parkinson (1915) recorded the case of a youth, aged 22, who was admitted to an isolation hospital on November 8, 1913, suffering from pharyngeal diphtheria. On November 30, he developed heart block, followed, on December 11, by auricular fibrillation, without any other evidence of myocardial damage. He was discharged from hospital on January 17, 1914, still fibrillating. Seen finally in June, he was still without symptoms and could walk seven miles without dyspnœa, but he was still fibrillating; how much longer it lasted is unknown. It was learnt that he was accepted for Army service in India in 1914, that he remained on active service until 1919, when he came home on leave after having had malaria; he was then in the best of health but six weeks later he developed pneumonia and died. This is the only case record similar to ours that we have found, but, owing to war conditions, we have been unable to make an exhaustive search. The occurrence of fibrillation as an isolated manifestation of myocardial damage in diphtheria is sufficiently rare to justify this case record.

\section{CASE Notes}

K.S.L., a dentist, aged 39, was serving in the R.A.F.V.R.

His mother had died of a stroke following hypertension. His father, aged 70 , had just recovered from an attack of hypertensive congestive failure. His brother had been confined to bed for two years, following what was stated to be a cardiac complication of measles.

He gave no history of any illness other than complaints of childhood. He had never had rheumatism or chorea. He had always been fit and well; a keen cyclist, he had cycled as much as 140 miles in a day. 
On October 6, 1942, he began to feel ill with a sore throat. He did not report sick until two days later, when a diagnosis of follicular tonsillitis was made and he was sent to bed. On October 12, he returned to duty, not feeling unduly ill but rather weak. In retrospect, he remembered seeing, on the first day of his illness, a greyish-white membrane on his throat, which disappeared after one day, leaving a red inflamed area. After a few days he felt much better and cycled 40 miles without undue fatigue.

On October 19 he began to get regurgitation of food through his nose, but, otherwise, felt well and continued at duty. He did not report sick until November 10, when the medical officer realized what was the matter; he was admitted to Torquay Isolation Hospital on the same day. On November 20 he noticed the sudden onset of tachycardia and irregularity of the pulse. It was considered that this was due to extrasystoles and, in view of the likelihood of mycardial damage, he was ordered complete rest. About this time he also noticed tingling of his hands and feet. About December 10 the palatal paresis began to improve and he was allowed to get up gradually. He was discharged to sick leave on December 19 . Whilst he was in hospital three throat swabs were taken, but all were negative for K.L.B.; no serum was given.

Whilst on sick leave he led a quiet life, walking short distances only. He felt reasonably well but was easily tired by quite mild exertion. Palpitation was conspicuous, occurring both at rest and on exertion, but he was not breathless. He also noticed an unpleasant tingling in his feet when walking about. On resuming duty, on February 23, 1943, he was referred to one of us (C.R.T.L.). The apex beat was displaced about half an inch to the left, and he was fibrillating, but without pulse deficit. The heart sounds were normal and the blood pressure approximately 140/80. There was some hypoalgesia over the soles of the feet and some loss of deep pain sense in the legs. Fibrillation was confirmed (P.C.G.; Fig. 1 A). He was trans-

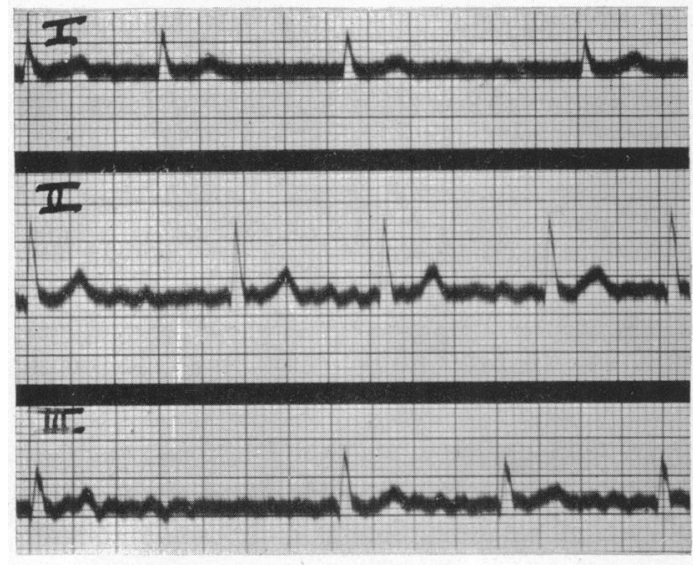

A

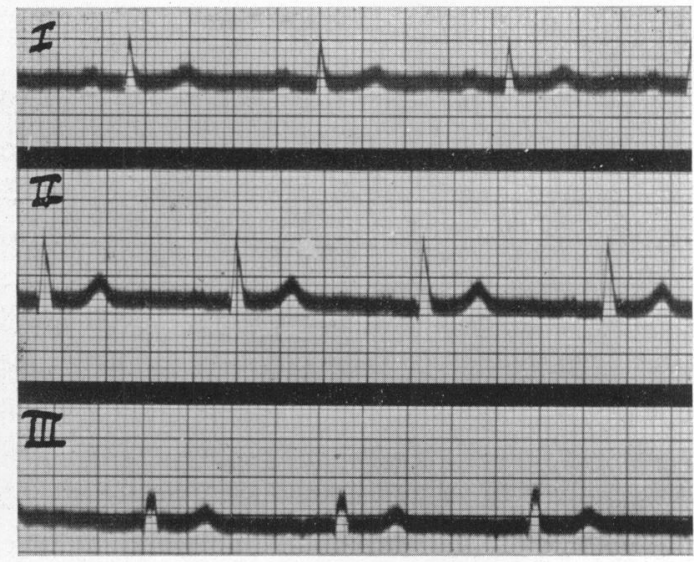

B

FIG. 1.-(A) Electrocardiogram taken $24 / 2 / 43$, showing auricular fibrillation. Rate about 80 .

(B) Electrocardiogram taken $23 / 4 / 43$, showing normal rhythm. Rate 68.

ferred to an R.A.F. Hospital, where a radiogram showed no enlargement, but his blood pressure was recorded as approximately 140/100. Quinidine, 5 grains t.i.d., was started on March 5, and after he had had 15 grains the pulse became regular. On April 19 he returned to duty feeling perfectly well. On that day he was seen by A.M.G.C., who found that his nervous system was normal, except for some weakness and displacement of the uvula to the right and diminished vibration sense in both legs. He gave an excellent history and, on being complimented on this, said he had been interested in his illness even to the point of introspection; only now did he refrain from taking his pulse every hour. The second electro- 
cardiogram (Fig. 1 B) showed no abnormality except small $P$ waves. The heart rate was 68 . The apex beat was in the fifth space, four and a half inches from the mid-sternal line, and was rather forcible. The blood pressure, sitting and recumbent, taken three times in each. position, was consistently $145 / 95$. The radial arteries did not seem thickened. The fundi

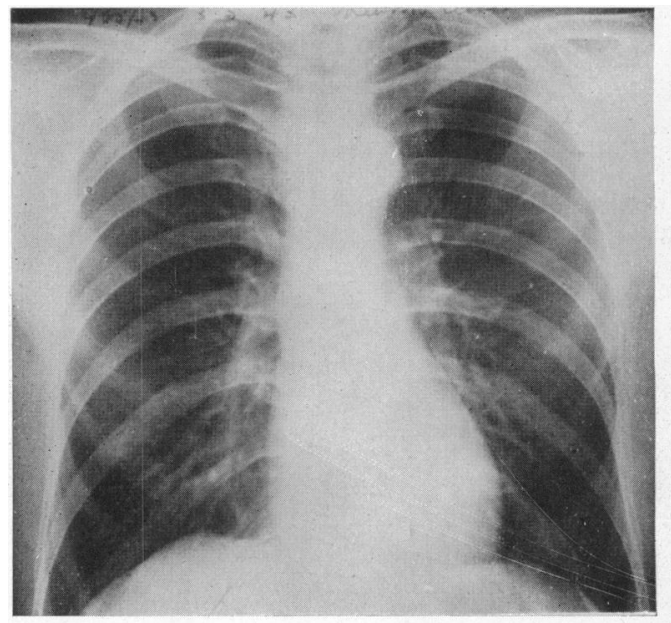

A

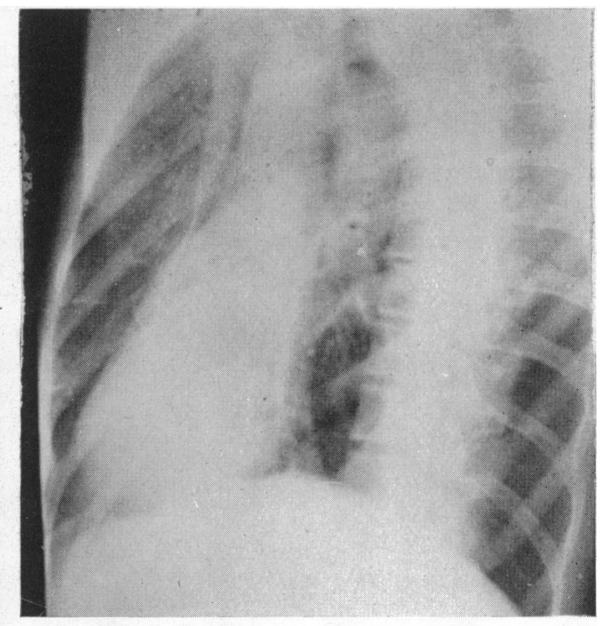

B

Fig. 2.-(A) Teleradiogram showing normal size of the heart.

(B) Teleradiogram in right anterior (II) oblique position.

were normal. Later, radiograms (Fig. 2) showed no enlargement of auricles or ventricles The urine was examined and found to be normal, chemically and microscopically.

\section{COMMENTARY}

The association of peripheral neuritis with myocardial damage in diphtheria is well known. Burkhardt et al. (1938) found the incidence of peripheral nerve palsies very high in those cases of diphtheria that showed electrocardiographic changes. From another angle, Walshe (1941) stated that in polyneuritis there is always some myocardial damage. Our case conforms with these views and supports the suggestion that it is desirable to seek for cardiographic changes in all cases of diphtheria, irrespective of severity, that have peripheral nerve lesions.

There is a possibility, emphasized by Geoffrey Bourne (1940) that some chronic local change in the heart, the commonest probably being vascular disease, may account for incomplete recovery after diphtheritic myocarditis. In our case there was a family history of arteriosclerosis and our patient himself showed some evidence of this, though only if his diastolic pressure is accepted as such.

Another feature of interest is the long period that elapsed after the onset of diphtheria before auricular fibrillation was established. This was also found in Parkinson's patient. In both cases fibrillation occurred during convalescence.

\section{SUMMARY}

In a man of 39 years old, we record auricular fibrillation, which arose during his convalescence from diphtheria. It lasted for 112 days, when it was stopped by quinidine. Except for his palpitation, it was unaccompanied by any symptoms referable to the cardiovascular system. It was associated with multiple peripheral neuritis, which preceded its onset by 32 days. There was a family history of arteriosclerosis and some slight evidence of this in the patient himself. 
We are indebted to the Medical Director General, R.N., and the Director General of Medical Services, R.A.F., for permission to publish this paper, to Wing Commander A. Nelson-Jones for supplying notes on treatment given at the R.A.F. hospital, and to Surgeon Commander A. R. Thomas, R.N.V.R., for the radiographic investigation, and we particularly wish to thank Dr. John Parkinson for his advice and assistance.

\section{REFERENCES}

Bourne, G. (1940). Lancet, $2,96$.

Burkhardt, E. A., Eggleston, C., and Smith, L. W. (1938). Amer. J. med. Sci., 195, 301.

Fishberg, A. M. (1940). Heart Failure, 2nd ed., 589. London.

Neubauer, C. (1942). Brit. med. J., 2, 91.

Pardee, H. E. B. (1942). Clinical Aspects of the Electrocardiogram, 4th ed. London.

Parkinson, J. (1915). Heart, 6, 13.

Walshe, F. M. R. (1941). Lancet, $1,33$.

White, P. D. (1938). Heart Disease, 2nd ed. New York. 